\title{
Implicit Memory and Consumer Choice: The Mediating Role of Brand Familiarity
}

\author{
SARAH L. COATES*, LAURIE T. BUTLER and DIANNE C. BERRY \\ School of Psychology, University of Reading, UK
}

\begin{abstract}
SUMMARY
Two experiments investigated the influence of implicit memory on consumer choice for brands with varying levels of familiarity. Priming was measured using a consideration-choice task, developed by Coates, Butler and Berry (2004). Experiment 1 employed a coupon-rating task at encoding that required participants to meaningfully process individual brand names, to assess whether priming could affect participants' final (preferred) choices for familiar brands. Experiment 2 used this same method to assess the impact of implicit memory on consideration and choice for unknown and leader brands, presented in conjunction with familiar competitors. Significant priming was obtained in both experiments, and was shown to directly influence final choice in the case of familiar and highly familiar leader brands. Moreover, it was shown that a single prior exposure could lead participants to consider buying an unknown, and indeed fictitious, brand. Copyright (C) 2006 John Wiley \& Sons, Ltd.
\end{abstract}

Implicit memory is defined as the non-intentional, non-conscious retrieval of previously acquired information, and is demonstrated by increased performance (typically referred to as priming) on tasks that do not require the conscious recollection of past experiences. Whilst theoretical aspects of implicit memory have been studied extensively over the past three decades, in recent years attention has started to focus on how implicit memory might affect behaviour in the real world. One area that has generated particular interest is consumer behaviour, where researchers have begun to explore links between implicit memory and judgement. However, one limitation that characterises much of this early work is that most choice scenarios have required participants to make a decision involving one or two brands (Butler \& Berry, 2002; Holden \& Vanhuele, 1999; Krishnan \& Shapiro, 1996; Lee, 2002; Perfect \& Edwards, 1998). This practice fails to adequately capture the complexity of real world choices.

To address this, Coates, Butler and Berry (2004) devised a series of experiments which explored the role of implicit memory using a more complex, and realistic, choice task. The task was broadly based upon a popular model of consumer choice devised by Shocker, Ben-Avika, Boccara and Nedungadi (1991), which has been used by a number of researchers as a basic framework for understanding how the consumer choice process might operate (see e.g. Baker, 1999; Desai \& Hoyer, 1994; Posavac, Sanbonmatsu,

*Correspondence to: S. L. Coates, School of Psychology, University of Reading, Earley Gate, Whiteknights, Reading. RG6 6AL, UK. E-mail: S.L.Coates@Reading.ac.uk

Contract/grant sponsor: Medical Research Council doctoral studentship; contract/grant number: G69/169.

Copyright (C) 2006 John Wiley \& Sons, Ltd. 
Cronley, \& Kardes, 2001; Shapiro, 1999; Shapiro, Macinnis, \& Heckler, 1997). The basic model identifies a series of hierarchical stages that the consumer must pass through before arriving at a final choice; the consumers' 'starting point' is a 'universal set' which refers to all of the alternatives of (most typically) branded products or services that could be purchased by the consumer at any particular time. Next the model describes an 'awareness set' which is a subset of (goal driven) items from the universal set that the consumer is aware of on a given occasion. Lastly, before a final choice can be made, the consumer constructs a 'consideration set,'which consists of goal satisfying alternatives that are salient or accessible on a particular occasion. It is from this (final) considered set of brands/ products that consumers are characterised as making their final choice.

In terms of empirical support, there is some evidence that consumers do indeed form consideration sets when making complex decisions. Firstly, Hauser and Wernerfelt (1990) reported that people consider only a subset of the total number of brands available for a particular category with most set sizes in the range of 3-6 items. In terms of cost/benefit trade-offs this makes sense, as it seems highly unlikely that a consumer would consider all possible alternatives when searching for a suitable product. Secondly, the consideration set has been shown to be critical to improving the predictive ability of quantitative/forecasting models within marketing (see e.g. Roberts \& Lattin, 1997). Lastly, Nedungadi (1990) provided direct evidence for the existence of a consideration 'stage' prior to choice, as he was able to demonstrate an effect on probability of choice by changing the probabilities of brand consideration without altering brand evaluations.

It should be noted however, that Nedungadi (1990) has suggested that a single-stage model incorporating elements of both consideration and choice might be 'more realistic' than a strictly two-stage model, as the boundaries between stages are often ill-defined, and the precise nature and dynamics of consideration remain somewhat unclear. For this reason Coates et al. (2004) devised and tested two versions of a complex choice task, one of which characterised consideration and choice stages as acting in parallel (i.e. as a single stage) and the other as acting sequentially (i.e. as two discrete stages). For both versions, Coates et al. found that previous exposure to familiar brand names (e.g. Clover margarine, Taylors coffee) increased the likelihood that they would enter the consumers' consideration set. However, this advantage was not found to extend to final choice itself.

Whilst the study reported by Coates et al. (2004) represents a significant step towards understanding the effects of implicit memory under real world conditions, two outstanding issues remain. The first concerns the extent of the boundary condition observed for priming on final choice. In order to simulate the superficial level of analysis that often accompanies brand name exposure (see e.g. Krugman, Dean, Cameron, \& White, 1995; Lynch \& Stipp, 1999), Coates et al. (2004, Experiment 2) employed a shallow encoding task that required participants to count the number of vowels in each brand name and product type. A subsequent comparison of the selection rates (i.e. likelihood of being considered for choice) for studied and non-studied brand names ( 0.68 and 0.61 , respectively) revealed a facilitatory priming effect of 0.07 . However, a key question is whether a larger priming effect would have had a more direct effect on choice. One way to explore this might be to use a more elaborative encoding task. Although depth of processing effects are often small in individual priming experiments (but see e.g. Thapar \& Greene, 1994), meta-analytical studies (e.g. Brown \& Mitchell, 1994; Challis \& Brodbeck, 1992) have shown that across experiments there is a consistent numerical advantage for elaborative over shallow encoding on perceptual implicit memory tasks. One likely explanation for this is that many shallow encoding tasks, including the vowel counting task employed by Coates et al. 
(2004), do not require participants to treat words (or brand names) as lexical units. The net effect may be to produce less priming than deeper encoding activities (see RichardsonKlavehn \& Gardiner, 1998). As such, a deeper, more elaborative encoding task might be expected to produce more priming on the implicit choice task. Therefore, the current study uses a new task that involves rating everyday coupon offers (e.g. 'money-off' coupons that accompany supermarket loyalty-card schemes or are found in magazines as part of an advertisement). It should be noted that this task is also more ecologically valid than the vowel counting task.

A second issue relates to the familiarity of the brand names being primed. Alba and Hutchinson (1987) define brand familiarity as a reflection of the brand-related experiences, which the consumer has accumulated over time. Whereas existing studies have explored implicit memory in choices where brand name familiarity has been held constant (e.g. Butler \& Berry, 2002; Chung \& Szymanski, 1997; Krishnan \& Shapiro, 1996; for an exception see Baker, 1999), it is apparent that most real product categories contain wellestablished familiar brands, alongside both brand leaders and new 'unfamiliar' brands entering the market for perhaps the first time. Thus, brand choices (notably stimulus-based choices) typically involve a search from a product category containing a mixture of brands, each with varying levels of familiarity, ranging from those with which consumers have had very few previous experiences (if any), to those which are highly familiar. Clearly then, it is important to ask whether priming can show any benefit for unfamiliar (completely unknown) brand names, and whether brand leaders (which by their nature are already highly likely to be selected over less familiar brands) stand to gain any benefit at all from the effects of priming.

To date, only a single study by Baker (1999) has investigated the influence of priming on choices for categories using a mixture of familiar and unknown brand name stimuli. Specifically, Baker found that priming unknown brands was only effective in choices involving other unknown, rather than familiar, brands. However, the extent to which priming differentially affects selection of unfamiliar (new) brands, familiar brands and brand leaders, has not been addressed. Previous research has shown that the probability of brand choice is dependent upon both the number and the nature of other brands in a consideration set (e.g. Baker, Hutchinson, Moore, \& Nedungadi, 1986), and that there is typically a positive link between brand familiarity and choice, such that, the more familiar a brand is over its competitors, the more likely it is to be chosen (e.g. Hoyer \& Brown, 1990; Monroe, 1976; Sundaram \& Webster, 1999). So whilst brand choice may be biased via priming, it is also possible that such effects will be mediated by the relative familiarity of the other brands in the set from which the consumer must choose.

From a theoretical perspective, the evidence regarding the effects of word familiarity on implicit memory is limited and mixed. For example, Postle and Corkin (1999) found robust priming for both familiar, and unfamiliar words on a perceptual identification task, although priming was impaired for unfamiliar words on a word stem completion task. Similarly, McKone (1995) reported faster decay of implicit memory for pseudo (unfamiliar) words, than for familiar words (using lexical decision and naming tasks). In contrast, Motomura (2003) demonstrated more priming for low familiarity words, than high familiarity words on a word stem completion task, whilst McKone \& Trynes (1999) found no effect of pre-experimental familiarity on priming using lexical decision and same-different judgement tasks. Therefore, it is difficult to predict how the magnitude of priming will be affected when participants are faced with a mixture of familiar and unknown/leader brands using the current complex choice task. Drawing on the findings of 
Baker (1999), it seems unlikely that a completely unknown brand (when competing against well-established, familiar brands) would stand to benefit from priming in terms of consideration or choice. Relatedly, brand leaders are by their nature, already highly likely to be chosen over a set of merely familiar brands and so might be expected to show less additional benefit from priming than familiar brands.

It is important then, from both a theoretical and an applied perspective, to ask whether the pattern of priming established in previous work (Coates et al., 2004) using a complex choice task, can be observed using a more elaborative encoding task and brands with varying levels of pre-established familiarity. Experiment 1 examines priming for familiar brands using a new, more realistic 'coupon rating' task at study. Experiment 2 subsequently investigates priming using a mixture of carefully constructed sets of real, highly familiar brand leaders, and unfamiliar (fictitious) brand name stimuli.

\section{EXPERIMENT 1}

Coates et al. (2004) reported that priming a familiar brand increased the likelihood that the brand would be considered for purchase, but had no effect on whether the brand was actually selected as the final preferred choice. The aim of Experiment 1 was to establish whether such a boundary condition would still be observed where familiar brand names were initially encoded using an elaborative 'coupon rating' task. The task was designed specifically to expose participants incidentally to target items, but in a more realistic, deeper and contextually relevant manner than the vowel-counting task previously used by Coates et al. (2004). Following the coupon rating task, and a filler task, the effects of priming on consideration and choice processes were examined using the implicit choice task devised by Coates et al. (2004, Experiment 2). Specifically, participants were asked, for each set of five labels (comprising brand names and product types) presented on screen, to choose three brands that they 'would actually buy, selecting them in order of preference,' such that the brand they selected first would be the brand which they 'most wanted to buy.' Hence position one represents 'first (i.e. considered and preferred) choice' and positions two and three represent 'considered only brands'. Note that this version of a complex choice task characterises consideration and choice stages as acting in parallel (i.e. as a single stage). However, in previous work comparable results have been produced regardless of whether a single or two stage choice task is employed (Coates et al., 2004). It is predicted that participants will be more likely to consider previously studied brand names than non-studied brand names. Additionally, compared to Coates et al. (2004), we expect the magnitude of priming to be enhanced. However, the crucial question is whether participants will be more likely to select previously studied brand names than non-studied brands as their final (preferred) choice.

\section{Method}

\section{Participants}

Twenty-eight undergraduates from The University of Reading participated in the experiment for research panel credit or for $£ 2$ payment. All participants were good English speakers and were tested individually. 


\section{Design}

A two factor (target type $\times$ selection order) within participant design was used. Target type had two levels (studied and non-studied), whereas selection order had three levels; first place (for consideration and choice), and second and third places (for consideration only).

\section{Materials}

Stimuli were taken from Coates et al. (2004). In constructing these stimuli, the aim was to generate a number of category sets, each consisting of real familiar brand names collated from (mainly) low-risk products found in everyday supermarkets. In order to control for factors such as inherent 'likeability', the selection of brand names was subjected to an extensive norming procedure. Questionnaires were distributed to 60 participants at The University of Reading, who rated each brand name on four dimensions; familiarity with the brand, frequency with which they purchased the brand, appeal of the brand, and the ease with which the brand name brought images to mind. This resulted in 120 brand names, which formed 24 category sets (of five brand names) in total. The brand names within each category were matched on all four dimensions, as well as, where possible, for word length. A target brand name (e.g. Danone) was selected for each category (e.g. Yoghurt) on the basis that it was not a brand leader, and was rated numerically lower than the other brand names on all four dimensions - most importantly 'familiarity.' The non-target brand names in each category served as distracters (e.g. Onken, Ski, Yoplait and Solo). Each category (e.g. margarine, washing powder) was assigned to one of two sets (Set A or Set B). Each set, comprising 12 categories, served as the studied set equally often. Thus, for example, when the 12 target brands from set A were shown at study and then again at test accompanied by matched distracters, the twelve non-studied targets from set B (presented with their respective distracters) served as baseline items.

Brand names and accompanying product types were presented on coupons in size 16 and size 14 point Arial font respectively, in conjunction with an offer (e.g. 2 for 1), barcode and other typical 'small-print' coupon information (see Figure 1). In total, two coupon 'booklets' were created, each containing 12 (familiar) target and 12 filler coupons (for sets A \& B), respectively. Each booklet was seven pages in length, including a cover page and six pages of coupons (four per page). Both target and filler coupons were presented in the same (mixed) order in each booklet. Coupon offers were always presented to the right of the brand name, and were always presented with the same product type (e.g. for crisps, the offer would always be 'Buy 1, get 1 free'). Coupons were printed in black ink and presented vertically down each white A4 page, and were numbered from 1 to 24 .

In order to direct attention towards the brand names, participants were given the relevant booklet and were asked to judge, on a 7-point rating scale (anchored by $1=$ 'very bad' and $7=$ 'very good'), 'how good' they thought each coupon offer was 'for the particular brand and product shown.' Prior to the experiment, questionnaires were distributed to 15 additional participants, who rated the coupon offers using the same scale. This norming procedure ensured that none of the target item offers was perceived as particularly good or poor, as one concern was that this might bias attitudes towards target brands independently of the priming manipulation. Overall, coupon offers for target items had a mean rating of 4.5. However, deliberately extreme offers (e.g. '75\% off $500 \mathrm{ml}$ bottles') were chosen for filler items to prevent acquiescence. Apart from the 


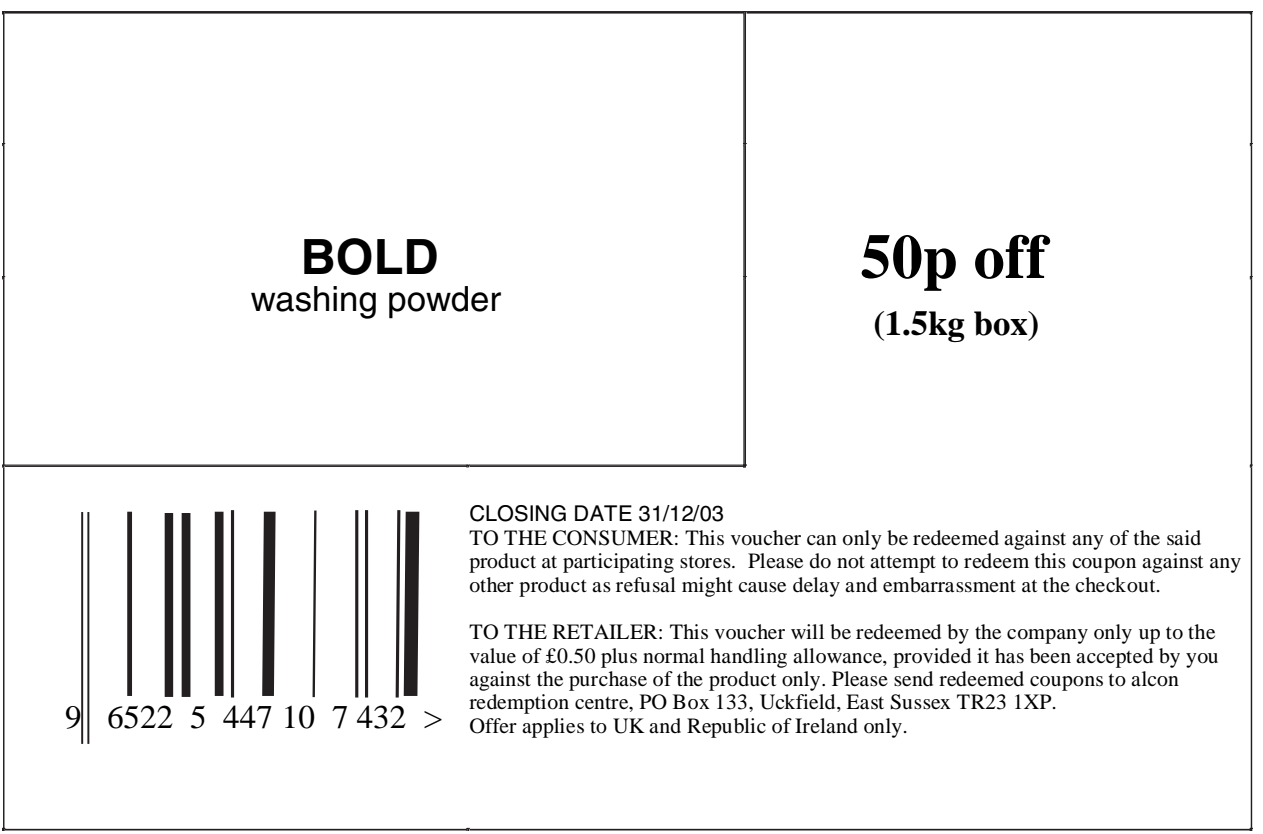

Figure 1. Typical ‘Coupon’ design

study phase, all other aspects of the experiment were identical to those employed by Coates et al. (2004, Experiment 2).

\section{Procedure}

Participants were seated individually at a table and were initially told that the experiment formed part of a wider investigation into consumer behaviour and that the first part was concerned with understanding why some coupon offers are perceived more positively by consumers than others (none was informed of the true aims of the study). Next, they were presented with a coupon booklet and response sheet, and were asked to rate each coupon (using the response sheet) according to 'how good' they thought the offer was 'for that particular brand and product.' Following a short filler task (a food-related 'consumer choice' questionnaire), participants were given written instructions for the test phase. For each set of five labels viewed on a computer screen, participants were asked to choose the three brands that they 'would actually buy, selecting them in order of preference' such that the brand they selected first, would be the brand which they would 'most want to buy'. They did this by clicking the mouse on the corresponding 'button' on screen. When the first brand was selected, the word 'First' appeared in red above that label as a reminder to participants (and likewise for 'Second' and 'Third' choices). Following the third selection, the instruction 'PRESS SPACEBAR' appeared in green below the five labels as a prompt to participants; the next set of labels then appeared on screen. Each set of labels was presented for 6 seconds before disappearing. In the unlikely event that brands disappeared before a choice was made, participants were still able to make their response via the selection buttons as these remained on screen. At the end of the experiment, a post-test awareness questionnaire was administered and participants were debriefed. 
Table 1. Selection order data for all participants: Familiar brands

\begin{tabular}{llcr}
\hline Selection Order & \multicolumn{1}{c}{ Target } & Selection Rate & Priming \\
\hline First & Studied & $0.30(0.11)$ & $0.14^{* *}$ \\
& Non-studied & $0.16(0.10)$ & -0.01 \\
Second & Studied & $0.23(0.10)$ & -0.02 \\
\multirow{2}{*}{ Third } & Non-studied & $0.24(0.10)$ & \\
& Studied & $0.17(0.10)$ & \\
& Non-studied & $0.19(0.10)$ & \\
\hline
\end{tabular}

${ }^{\text {a }}$ Proportion of targets selected. Standard deviations shown in parentheses.

** Significant at $p<0.005$.

\section{Results}

Table 1 shows the mean proportion of targets correctly selected as a function of target type (studied \& non-studied), and selection order (1st, 2nd or 3rd place) for all 28 participants. These proportions correspond to the proportion of studied and non-studied targets that were selected 'in order of preference' by participants. A 2 (target type) $\times 3$ (selection order) repeated measures ANOVA was conducted.

\section{Implicit choice data}

Overall, there was a main effect of target type $(\mathrm{F}(1,27)=10.28, p=0.005)$ which, given selection rates for studied and non-studied items of $0.70(S D=0.14)$ and $0.59(S D=0.11)$, respectively, indicated a highly significant priming effect of 0.11 .

\section{Consideration only data}

The consideration only data comprised those brands selected in second and third positions. There was a main effect of selection order $(\mathrm{F}(2,54)=4.83, p=0.01)$ and, more crucially, a significant interaction $(\mathrm{F}(2,54)=6.51, p=0.005)$ with target type. Bonferroni corrected t-tests revealed no significant effect of priming for items selected in second position $(\mathrm{t}(27)=-0.21, p>0.05)$, or 3rd position $(\mathrm{t}(27)=-0.75, p>0.05)$. Therefore, brand names in these positions were no more likely to be selected for consideration, than those brands that had not been previously seen. As such, the interaction must be due to a priming effect for items selected in first (considered and preferred) place.

\section{Preferred choice data}

The selection rate for studied brand names was $0.30(S D=0.11)$, and the rate for nonstudied brands was $0.16(S D=0.10)$. This priming effect of 0.14 was highly significant $(\mathrm{t}(27)=4.72, p<0.001)$ indicating that priming influenced preferred choice. Brands, which had been previously exposed, were significantly more likely to be selected by participants as their preferred choice, than previously non-studied ones.

\section{Test unaware data}

A second analysis was conducted on the basis of participants' responses to post-test awareness questionnaires (see Bowers \& Schacter, 1990; Coates et al., 2004). Accordingly, 16 participants were classified as test unaware. Overall, the resulting pattern of priming was the same as for the whole sample. For brands selected in 1st place (as preferred choice) 
there was a priming effect of 0.15 , with selection rates of $0.30(S D=0.13)$ and $0.15(S D$ 0.11 ) for studied and non-studied items, respectively. This effect was significant $(\mathrm{t}(27)=3.29, p=0.005)$ and indicated that priming facilitated preferred choice, even for participants who claimed to be test unaware.

\section{Discussion}

As predicted, the results of Experiment 1 showed that previously studied brand names were significantly more likely to be selected than non-studied ones. In addition to this, it was shown that all of the positive priming occurred in first place (for preferred choice). There was no significant priming at the consideration only stage. Furthermore, the same pattern of findings was obtained when only the data for test unaware participants was analysed. These results are particularly notable as, compared to Coates et al. (2004), the present experiment has shown that priming for familiar brand names can extend beyond the stage of consideration, to influence participants' preferred choices. This change may reflect the increase in overall priming ( 0.07 to 0.11$)$ observed in the two experiments.

We defer further consideration of this new finding until the General Discussion to permit us to focus on the second important issue, namely, whether the facilitation that results from priming for familiar brands would be sufficient to cause a completely unfamiliar brand to be considered, or even chosen over, a group of more familiar brands. Additionally, whether highly familiar brand leaders would gain any additional benefit from priming in terms of selection over other familiar brands. In the case of highly familiar leader brands, there are a number of different dimensions that could be used to inform choice (e.g. attitudes based on prior experiences with the brand, brand image and performance attributes). As such, priming may provide a relatively unimportant additional source of information in this instance. Thus, Experiment 2 will examine priming for both unknown (unfamiliar) brands, and for brand leaders.

\section{EXPERIMENT 2}

The aim of Experiment 2 was to examine the effects of priming on brand consideration and choice for both unknown brands and for brand leaders, when presented alongside a set of moderately familiar brands. In the real world, consumers are typically faced with situations in which they must choose from among a number of brands, some of which may be reasonably familiar, some of which may be very well-known brand leaders, and others which may be completely unknown to the consumer. Previously, research in this area has tended to focus on choices from among (typically) just two brands, both of which are either unfamiliar (e.g. Butler \& Berry, 2001a; 2001b; Krishnan \& Shapiro, 1996) or familiar (e.g. Chung \& Szymanski, 1997; Coates et al., 2004). None as yet has looked at the effects of priming on brand leaders (which by their nature are highly familiar), and none (with the exception of Baker, 1999) has attempted to look at choices from among a set of brands of mixed familiarity. Therefore, the extent to which priming can influence both consideration and choice of an unknown brand over four familiar brands, is unclear. Likewise, it is uncertain whether brand leaders can accrue any additional benefit from priming, in the context of four familiar brands. Experiment 2 therefore employed the same procedure as Experiment 1, however, the influence of priming on unknown brands and on brand leaders was examined in the context of (moderately) familiar distracter brands. 
It is expected that unknown brands will show little benefit, if any (in terms of consideration or choice), when competing against well-known, and established familiar brand stimuli, as participants are already likely to hold pre-existing knowledge/experience of the familiar (distracter) brands. For brand leaders, we expected any effects of priming to become apparent at first (preferred) choice, provided these stimuli are not already chosen at ceiling levels.

\section{Method}

\section{Participants}

Fifty-six undergraduates from The University of Reading participated in the experiment for research panel credit or for $£ 2$ payment. All participants were good English speakers and were tested individually. None had taken part in Experiment 1.

\section{Design}

A three factor (target familiarity $\times$ target type $\times$ selection order) mixed participants design was employed. Target familiarity had two levels (leader brand $\&$ unknown brand) and was manipulated between participants, target type had two levels (studied \& non-studied) and was manipulated within participants, whilst selection order had three levels; 1st place (for consideration and choice), and 2nd and 3rd places (for consideration only) and was manipulated within participants. Whilst 12 brand leader and unknown target stimuli were used in this design, it was not possible to create an additional 12 leader brands for the test phase due to constraints on the number of available stimuli. Specifically, from the original product categories of familiar brands which were normed prior to Experiment 1, only 12 sets contained a brand name which scored sufficiently high on the familiarity dimension to be classified as a brand 'leader'. Therefore, the leader and unknown brand conditions were combined, such that participants in the former condition saw 12 (primed) leader brands (e.g. Walkers crisps) and their accompanying distracter sets (e.g. Smiths, Kettle, Crown, and Bensons), and also provided baseline (non-studied) data for the 12 unknown target brands (e.g. Goldews lager) and their accompanying sets (e.g. Grolsch, Carlsberg, Carling, and Heineken) in the test phase. The reverse was the case for participants allocated to the unknown brand condition.

\section{Materials}

Whilst we were able to use the same categories of familiar brand names as distracters (e.g. Mentadent, Ultrabrite, Signal, and Clinomyn toothpaste; Palmolive, Dove, Nivea and Vaseline deodorant) as employed in Experiment 1, two new sets of brand name targets were created for use alongside the existing familiar brands; these were a set of real, highly familiar brand leaders (e.g. Colgate toothpaste), and a set of unknown (fictitious) brand names (e.g. Bare deodorant). In creating the stimuli, 12 highly familiar brand leaders were chosen to serve as targets among the existing groups of familiar brand names. These were selected from the initial categories of brand names developed and normed prior to our 2004 study. For each of 12 (of the total 24) groups of brand names, one brand was chosen (from the initial norming list) which was found to score particularly highly on the dimensions of 'familiarity of the brand' and 'frequency with which participants purchased the product', in comparison to the four existing distractor brands in that group (obvious brand leaders were not available for all 24 initial categories). For each of the remaining 12 groups, an unknown brand name was created to serve as the target brand. To produce these, three fictitious brand 
names for each product type were created which were then distributed to 15 participants studying at The University of Reading. Participants were required to rate each brand along three relevant dimensions. These were 'familiarity of the brand,' 'how fitting the brand name is for the product category,' and 'does the brand remind you of any other well-known brands because it either looks like or sounds like that brand name' (participants were also encouraged to write down any particular brands that came to mind). Furthermore, several real brand names were interspersed amongst the unknown brands in order to make the task of the brand rating appear more meaningful. Ratings were made on 6-point liking scales anchored by 'not at all' and 'very.' The final set of 12 brands, selected to serve as targets, were matched as closely as possible on the three dimensions - they were found to score low on familiarity, high on how fitting the brand name was, and were only selected if they did not remind participants of other well-known brands. Finally, brands were also matched for word length with the targets used in Experiment 1. As before, target stimuli were presented at study via a coupon booklet. Whilst these were normed and fully randomised in the same way, both leader brand and unknown brand booklets contained an additional 12 filler coupons in an attempt to minimise potential test awareness. Consequently, each booklet was nine pages in length and contained a total of 36 brands (12 leader or unknown targets \& 24 familiar filler items). Mean familiarity ratings for unknown, familiar, and leader brands were (on a scale of 1-6) 1.2, 3.2 and 5.2, respectively. All other aspects of the experiment were identical to Experiment 1.

\section{Procedure}

The procedure was identical to Experiment 1 with the exception that, depending on the experimental condition, participants were given either the coupon booklet containing leader brand targets, or unknown brand targets.

\section{Results}

As the experiment was concerned with establishing the independent contribution of priming to the selection of leader and unknown brands, respectively, the data for each was analysed separately using two 2 (target type) $\times 3$ (selection order) mixed design Anovas.

\section{Leader brand condition}

Table 2 shows the mean proportion of targets correctly selected as a function of target type (studied \& non-studied), and selection order (1st, 2nd or 3rd place) for all 56 participants.

Table 2. Selection order data for all participants: Leader brands

\begin{tabular}{llcr}
\hline Selection Order & \multicolumn{1}{c}{ Target } & Selection Rate & Priming \\
\hline First & Studied & $0.84(0.08)$ & $0.10^{\text {*** }}$ \\
& Non-studied & $0.74(0.13)$ & -0.05 \\
Second & Studied & $0.08(0.08)$ & 0 \\
\multirow{2}{*}{ Third } & Non-studied & $0.13(0.11)$ & 0 \\
& Studied & $0.05(0.05)$ & \\
& Non-studied & $0.05(0.06)$ & \\
\hline
\end{tabular}

${ }^{a}$ Proportion of targets selected. Standard deviations shown in parentheses.

${ }^{* *}$ Significant at $p<0.005$. 
These proportions correspond to the proportion of studied and non-studied targets that were selected 'in order of preference' by participants.

Implicit choice data. There was a main effect of target type $(\mathrm{F}(1,54)=5.95, p=0.01)$. The selection rates for studied and non-studied items were $0.97(S D=0.04)$ and 0.92 $(S D=0.18)$, respectively, indicating a significant overall priming effect of 0.05 .

Consideration only data. The consideration only data comprised those brands selected in second and third positions. There was a significant main effect of selection order $(\mathrm{F}(2,108)=774.7, \quad p<0.001)$ and a significant interaction with target type $(\mathrm{F}(2,108)=6.01, p=0.003)$. Regarding this interaction, there was no evidence of any priming in 3rd place (studied and non-studied selection rates were both 0.05 ) and no significant priming at 2 nd place $(\mathrm{t}(54)=-1.82, p=0.07) .{ }^{1}$ Therefore, the results show that leader brands to which participants were previously exposed, were no more likely to be selected for consideration than non-studied leader brands.

Preferred choice data. The selection rate for studied brand names was $0.84(S D=0.08)$ whereas the rate for non-studied brands was $0.74(S D=0.13)$. This priming effect of 0.10 was highly significant $(\mathrm{t}(47)=3.14, p=0.003)$, indicating that leader brands to which participants were previously exposed, were significantly more likely to be selected as their preferred choice than non-studied brands.

Test unaware data. Using the criteria specified by Coates et al. (2004), 20 participants assigned to the leader condition were classified as test unaware. The pattern of priming was the same as for the whole sample such that previously studied leader brands were significantly more likely to become participants' final (preferred) choice than nonstudied brands, with selection rates of $0.84(S D=0.09)$ and $0.74(S D=0.15)$ for studied and non-studied items, respectively. This priming effect of 0.10 was significant $(\mathrm{t}(34)=2.53, p=0.01)$.

\section{Unknown brand condition}

Table 3 shows the mean proportion of targets correctly selected as a function of target type (studied \& non-studied), and selection order (1st, 2nd or 3rd place) for all 56 participants. These proportions correspond to the proportion of studied and non-studied targets that were selected 'in order of preference' by participants.

Table 3. Selection order data for all participants: Unknown brands

\begin{tabular}{llcc}
\hline Selection Order & \multicolumn{1}{c}{ Target } & Selection Rate $^{\mathrm{a}}$ & Priming \\
\hline First & Studied & $0.05(0.06)$ & 0.02 \\
& Non-studied & $0.03(0.05)$ & 0.02 \\
Second & Studied & $0.06(0.06)$ & 0.04 \\
\multirow{2}{*}{ Third } & Non-studied & $0.04(0.05)$ & $0.08(0.08)$ \\
& Studied & $0.04(0.04)$ & \\
\hline
\end{tabular}

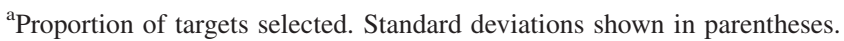

\footnotetext{
${ }^{1}$ The trend towards significance here, suggests that priming is having the effect of 'shifting' brands up from second to first place, hence the apparent negative effect.
} 
Implicit choice data. There was a significant main effect of target type $(\mathrm{F}(1,54)=14.70$, $p<0.001)$. The selection rates for studied and non-studied items were $0.20(S D=0.08)$ and $0.12(S D=0.06)$ respectively, indicating a significant priming effect of 0.08 .

Consideration only data. The consideration only data comprised those brands selected in second and third positions. There was no significant main effect of selection order $(\mathrm{F}(2,108)=0.91, p>0.05)$, and no significant interaction $(\mathrm{F}(2,108)=0.09, p>0.05)$. Therefore, the results show that priming has no significant effect on the specific order in which unknown brands are selected, and so the distinction cannot be drawn between priming for considered brands, and priming for preferred choice. However, as the overall implicit choice data shows, priming does confer a general benefit in the sense that those brands which have been previously exposed, are more likely to be selected (either considered or chosen), than those which have not.

Test unaware data. As above (according to responses to the post-test awareness questionnaires), 16 participants assigned to the unknown condition were classified as test unaware. As was the case for the whole sample, there was a significant main effect of target type $(\mathrm{t}(34)=3.57, p<0.001)$, with a priming effect of 0.09 . Selection rates were 0.21 $(S D=0.09)$ and $0.12(S D=0.06)$ for studied and non-studied brands, respectively. Therefore priming conferred a general benefit to unknown brands, even under these more stringent conditions.

\section{Discussion}

In summary, the results of Experiment 2 showed that for both leaders and unknown brands previously studied brands were significantly more likely to be selected than non-studied brands. In addition to this, it was found that leader brands were significantly more likely to be selected in first place (as participants' preferred choice) than non-studied brands, whereas unknown brands were shown to benefit from a significant general (i.e. nonspecific) effect of priming. Furthermore, these effects were found to be significant when only test unaware data were analysed.

\section{GENERAL DISCUSSION}

The purpose of this study was to investigate the effects of elaborative encoding on implicit memory for unknown, familiar and leader brand names in a complex choice task. Experiment 1 showed that following a coupon-based encoding task, familiar brand names were primed for final (preferred) choice over a set of four equally familiar brands. Experiment 2 demonstrated a broadly parallel pattern using brand leaders. Moreover, it was shown that priming was even sufficient to facilitate the selection of completely unknown brand names over familiar ones.

Contrary to the findings reported here (for both familiar brands and brand leaders), Coates et al. (2004) found that priming familiar brands encouraged participants to consider previously studied items but did not influence their final choice. In explaining these conflicting findings one explanation is that the shift from consideration only to final choice across the two studies reflects the relative strength of priming produced by the shallow vowel counting task used by Coates et al. (2004) and the more elaborative coupon task 
employed here. In support of this, we calculated effects sizes based on the overall priming effects obtained by Coates et al. (2004) and in the current study. As the experiments reported by Coates et al. (2004) employed familiar brand names, only Experiment 1 from the current study was included as this drew on the same corpus of familiar brand names. Whilst Experiments 1 and 2 reported by Coates et al. (2004) ${ }^{2}$ using a vowel counting study task yielded effect sizes of $r^{2}=0.13$, and $r^{2}=0.15$, respectively, a much larger effect size of $r^{2}=0.28$ was obtained in the current study (Experiment 1 ). This latter effect size constitutes a large effect $\left(\mathrm{r}^{2} \geq 0.25\right)$ according to the convention proposed by Cohen (1988). Thus, the introduction of the coupon study task has substantially increased an initially small effect. Although such comparisons should be interpreted with caution, it seems likely that the extent of the impact of implicit memory on consumer choice may thus depend on the quality of the initial exposure to the brand name. At first glance, the observation that priming is greater where the initial exposure encourages meaningful rather than non-meaningful part-based processing may not seem surprising. However, the crucial point is that this may dictate whether implicit memory will have a direct impact on choice or not. One may speculate that stronger priming operates more directly on choice because it is less likely to be 'drowned out' or ignored in preference to other types of information (e.g. pre-experimental favourites, brand attribute information). Whilst a definitive explanation must await future research, the implications and challenge for advertisers is clear.

Traditionally, depth-of-processing manipulations have been thought to have little effect on implicit memory performance (e.g. Graf \& Mandler, 1984). However, as mentioned in the introduction, across studies there is a highly consistent numerical advantage for deep over shallow processing at study (Brown \& Mitchell, 1994; Challis \& Brodbeck, 1992). In interpreting the current findings, our preferred explanation is that vowel counting produces less priming because it focuses attention onto individual letters rather than encouraging whole word (or lexical processing). Richardson-Klavehn and Gardiner (1998) provide support for this interpretation. Alternatively, it may be that our implicit choice task is sensitive to conceptual/semantic processing as well as to perceptual processing (e.g. Hirshman, Snodgrass, Mindes, \& Feenan, 1990). One final explanation though is that depth of processing effects on implicit memory tasks reflect contamination by explicit retrieval strategies (e.g. Reingold \& Toth, 1994). However, this seems unlikely in the present case as in both Experiments 1 and 2 substantial priming was shown even for participants who claimed to have no awareness that brand names appearing during the choice task had previously been presented at study.

Perhaps the most striking finding from the current study was that a single exposure to a previously unknown brand name was sufficient to cause a small but reliable increase in the selection rate of that brand name over already established (familiar) brand names. ${ }^{3}$ This finding should be of particular concern to brand managers and food companies who spend over 17 billion pounds per annum (Advertising Association Forecast, March 2004) promoting awareness of their products to maintain brand share. Overall, the priming effect for unfamiliar brands was small and was not found to be specific to brand consideration or

\footnotetext{
${ }^{2}$ A third experiment reported by Coates et al. (2004) is not reported here as the overall priming effect was negligible, although the priming observed for second placed brands was significant $(p=0.01)$.

${ }^{3}$ Note that the apparent discrepancy between the results of the current study and Baker (1999) likely reflects the fact that the contrast of interest in the latter study was whether participants chose a single unknown brand over a single familiar brand. In the current study, the question was whether an unknown brand would be selected as one of three preferred brands.
} 
choice. Presumably this is because the presence of familiar 'competitor' brands in the test phase (which by definition, consumers have been exposed to more frequently in the past) offsets, to a certain degree, the extent of any potential benefit of priming. Jones (1994) points out that for many everyday grocery products, new brands are often regarded as similar to those that already exist, and so are relatively easily assimilated into existing category structures in memory. Therefore, priming may serve to enhance this assimilation. Furthermore, there is evidence to suggest that a single prior exposure of a novel stimulus (in the absence of conscious awareness of that exposure) can lead individuals to attribute false familiarity to that stimulus (Holden \& Vanhuele, 1999). In such cases, implicit memory may lead consumers to falsely perceive new/unknown brands to be old/existing brands. In this way the gap between new brands entering the market, and brand leaders in that market, might be narrowed.

One potential criticism that might be levelled at the current study is that participants were not treating the choice task in the same way as they would a series of real choices. Indeed, one might argue that participants were not treating the task seriously and were simply selecting 'any brand' because their decisions had no real consequences. In this context, the finding that unfamiliar brand names could be primed over established brands would be less noteworthy. However, there are two reasons to doubt that this is the case. Firstly, inspection of the selection rates (studied) for the unknown, familiar and leader brands $(0.05,0.30 \& 0.84$, respectively) demonstrates that participants were not selecting 'any brand' but rather were carefully discriminating between different types of brand. Secondly, and more importantly, using exactly the same version of the choice task as used in Experiment 1, we have shown (Coates et al., 2004; Experiments $2 \& 3$ ) that participants perform in the same way regardless of whether they actually physically receive some of the brands they select or not. This suggests that participants do take the choice task seriously, indeed as seriously as they would an actual choice.

One limitation to these studies is that it is possible that participants received more than one single exposure to some of the target coupons. Unfortunately this type of compromise over experimental control is somewhat inevitable if increased realism is the desired outcome. Despite this limitation, the new coupon task appears to be a very effective way of producing priming effects whilst capturing some aspect of how brand names might be encoded in the real world. Finally, and notwithstanding the relevance of these findings, consumers are typically faced with an array of products that vary in terms of packaging shape and colour, as well as the brand names themselves. Work is currently underway in our laboratory to explore priming for actual products with these features.

In summary, the two experiments reported here, have shown compelling evidence for the influence of priming on brand consideration and/or choice for brands of mixed familiarity (when presented alongside moderately familiar alternatives). These effects have also been found (largely) in the absence of awareness of the study episode, using a relatively realistic encoding task and following just a single exposure to target brands.

\section{ACKNOWLEDGEMENTS}

This research was supported by a Medical Research Council doctoral studentship (G69/ 169) to S. L. Coates. We would like to thank Tim Perfect and an anonymous referee for their useful comments on an earlier draft of this article. 


\section{REFERENCES}

Alba, J. W., \& Hutchinson, J. W. (1987). Dimensions of consumer expertise. Journal of Consumer Researc, 13, 411-454.

Baker, W. E. (1999). When can affective conditioning and mere exposure directly influence brand choice? Journal of Advertising, 27, 31-46.

Baker, W., Hutchinson, J. W., Moore, D., \& Nedungadi, P. (1986). Brand familiarity and advertising: effects on the evoked set and brand preference. Advances in Consumer Research, 13, 637-642.

Bowers, J. S., \& Schacter, D. L. (1990). Implicit memory and test awareness. Journal of Experimental Psychology: Learning, Memory and Cognition, 16, 404-416.

Brown, A. S., \& Mitchell, D. B. (1994). A reevaluation of semantic versus nonsemantic processing in implicit memory. Memory and Cognition, 22, 533-541.

Butler, L. T., \& Berry, D. C. (2001a). Implicit memory: Intention and awareness revisited. Trends in Cognitive Sciences, 5, 192-197.

Butler, L. T., \& Berry, D. C. (2001b). Transfer effects in implicit memory and consumer choice. Applied Cognitive Psychology, 15, 1-15.

Butler, L. T., \& Berry, D. C. (2002). The influence of affective statements on performance on implicit and explicit memory tasks. Applied Cognitive Psycholog,y 16, 829-843.

Challis, B. H., \& Brodbeck, D. R. (1992). Level of processing affects priming in word fragment completion. Journal of Experimental Psychology-Learning Memory and Cognition, 18, 595-607.

Chung, S. W., \& Szymanski, K. (1997). Effects of brand name exposure on brand choices: An implicit memory perspective. Advances in Consumer Research, 24, 288-295.

Coates, S. L., Butler, L. T., Berry, D. C. (2004). Implicit memory: A prime example for brand consideration and choice. Applied Cognitive Psychology. 18, 1195-1211.

Cohen, J. (1988). Statistical Power Analysis for the Behavioural Sciences. Hillsdale, NJ: Erlbaum.

Desai, K., \& Hoyer, W. D. (1994). Memory, product familiarity, and categorisation influences on the composition of consideration sets. Advances in Consumer Research, 21, 436.

Graf, P., \& Mandler, G. (1984). Activation makes words more accessible, but not necessarily more retrievable. Journal of Verbal Learning \& Verbal Behaviour, 23, 553-568.

Hauser, J. R., \& Wernerfelt, B. (1990). An evaluation cost model of evoked sets. Journal of Consumer Research, 16, 393-408.

Hirshman, E., Snodgrass, J. G., Mindes, J., \& Feenan, K. (1990). Conceptual priming in fragment completion. Journal of Experimental Psychology: Learning, Memory \& Cognition, 16(4), 634647.

Holden, S. J. S., \& Vanhuele, M. (1999). Know the Name, forget the exposure: Brand familiarity versus memory of exposure context. Psychology and Marketing, 16, 479-496.

Hoyer, W. D., \& Brown, S. P. (1990). Effects of brand awareness on choice for a common, repeatpurchase product. Journal of Consumer Research, 17, 141-148.

Jones, M. (1994). Differentiating new Brands: Product category judgements as mediators of new product evaluation processes. Advances in Consumer Research, 1, 17-21.

Krishnan, H. S., \& Shapiro, S. (1996). Comparing implicit and explicit memory for brand names from advertisements. Journal of Experimental Psychology: Applied, 2, 46-162.

Krugman., Dean., Cameron, D., White, C. (1995). Visual attention and commercials: The use of Inhome observations. Journal of Advertising Research.. 24, 1-12.

Lee, Y. (2002). Levels of processing and phonological priming in Chinese character completion tests. Journal of Psycholinguistic Research, 31, 349-362.

Lynch, K., Stipp, H. (1999). Examination of Qualitative viewing factors for optimal advertising strategies. Journal of Advertising Research. 39, 7-16.

McKone, E. (1995). Short-term implicit memory for words and nonwords. Journal of Experimental Psychology-Learning Memory and Cognition, 21, 1108-1126.

McKone, E., \& Trynes, K. (1999). Acquisition of novel traces in short-term implicit memory: Priming for nonwords and new associations. Memory \& Cognition, 27, 619-632.

Monroe, K. B. (1976). The influence of price differences and brand familiarity on brand preferences. Journal of Consumer Research, 3, 42-49.

Motomura, N. (2003). Word familiarity influences word-stem completion in amnesic patients. Perceptual and Motor Skills, 96, 847-853. 
Nedungadi, P. (1990). Recall and consumer consideration sets: Influencing choice without altering brand evaluations. Journal Of Consumer Research, 17, 263-276.

Perfect, T. J., \& Edwards, A. (1998). Implicit memory for radio advertising. Psychological Reports, 83, 1091-1094.

Posavac, S. S., Sanbonmatsu, D. M., Cronley, M. L., \& Kardes, F. R. (2001). The effects of strengthening category-brand associations on consideration set composition and purchase intent in memory-based choice. Advances in Consumer Research, 28, 186-189.

Postle, B. R., \& Corkin, S. (1999). Manipulation of familiarity Reveals a necessary lexical component of the word-stem completion priming effect. Memory and Cognition, 27, 12-25.

Reingold, E. M. \& Toth, J. P. (1994). Process dissociations versus task dissociations: A controversy in progress. In G. Underwood (Ed.), Implicity cognition. Oxford: Oxford University Press.

Richardson-Klavehn, A., \& Gardiner, J. M. (1998). Depth-of-processing effects on priming in stem completion: Tests of the voluntary-contamination, conceptual-processing and lexical-processing hypotheses. Journal of Experimental Psychology: Learning, Memory and Cognition, 24, 593-609.

Roberts, J. H., \& Lattin, J. M. (1997). Consideration: Review of research and prospects for future insights. Journal of Marketing Research, 34, 406-410.

Shapiro, S. (1999). When an ad's influence is beyond our conscious control: Perceptual and conceptual fluency effects caused by incedental Exposure. Journal of Consumer Research, 26, $16-36$.

Shapiro, S., Macinnis, D. J., \& Heckler, S. E. (1997). The effects of incedental ad exposure on the formation of consideration sets. Journal of Consumer Research, 24, 94-104.

Shocker, A. D., Ben-Akiva, M., Boccara, B., \& Nedungadi, P. (1991). Consideration set influences on consumer decision-making and choice: Issues, models and suggestions. Marketing Letters, 2, 181-197.

Sundaram, D. S., \& Webster. (1999). The role of brand familiarity on the impact of word-of-mouth communication on brand evaluations. Advances in Consumer Research, 26, 664-670.

ThaparA., \& Greene, R. L. (1994). Effects of level of processing on implicit and explicit tasks. Journal of Experimental Psychology-Learning Memory and Cognition, 20, 671-679. 
Copyright of Applied Cognitive Psychology is the property of John Wiley \& Sons Inc. and its content may not be copied or emailed to multiple sites or posted to a listserv without the copyright holder's express written permission. However, users may print, download, or email articles for individual use. 